\title{
Antimicrobial Photodinamic Therapy Combined with Laser Photobiomodulation in the Treatment of Skin Wounds in a Dog (Canis lupus familiaris)
}

\author{
Fernando Alzamora Filho ${ }^{1}{ }^{1}$, Manoel Luiz Ferreira ${ }^{2}{ }^{2}$, Marcus Vinícius Alves da Silva ${ }^{2}{ }^{2}$, \\ Anna Claudia Mombrini Silva Barbosa $\mathbb{D}^{3}$, Bruna Guedes Carvalho $\mathbb{D}^{4}$, Marcel Vasconcellos $\mathbb{D}^{5}$, \\ José Marcus Raso Eulálio (iD ${ }^{2} \&$ José Eduardo Ferreira Manso ${ }^{2}{ }^{2}$
}

\begin{abstract}
Background: Laser photobiomodulation has been used in the treatment of various injuries and diseases. This promotes modulation of the inflammatory process, edema reduction and devitalized tissue regeneration. The advantages of Antimicrobial photodynamic therapy are its easy application and the absence of side effects. Other advantages are the cost of the therapy, minimal damage to animal tissue, the broad spectrum of action, and efficiency against strains resistant to antimicrobials. The aim of this study was to report the clinical and their resolution in a female dog with a traumatic, infected wound treated with laser phototherapy as an alternative therapy method.

Case: A 3-year-old bitch Border Collie, weighing $18 \mathrm{~kg}$, from the municipality of Ilhéus, Bahia, Brazil, was presented for examination with a history of traumatic laceration of the left thoracic member. On the anamnesis, it was reported that the patient presented with laceration of the left thoracic member. The wound was cleaned and an antibiotic [ $30 \mathrm{mg} / \mathrm{kg}$ of $12 / 12 \mathrm{~h}$ ] and anti-inflammatory [0.1 mg/kg every $24 \mathrm{~h}$ were prescribed, both for 5 days]. Twenty-four $\mathrm{h}$ after the surgical procedure, there was dehiscence of the sutures, with daily topical therapy based on zinc oxide for secondary intention healing. Upon physical examination, the wound was found to be contaminated with swollen and erythematous edges, an ulcerated area with devitalized tissue, serous exudate, and $8.8 \mathrm{~cm}^{2}$ of wounded area. Given the macroscopic characteristics of the lesion, phototherapy was associated with conventional therapy until complete healing of the wound, with three weekly applications at $48 \mathrm{~h}$ intervals. Initially, the wound was cleaned with saline solution at $0.9 \%$ and a single treatment with aPDT was scheduled due to the high degree of contamination. The dosimetry parameters of irradiation were calculated according to the wounded area with a diode laser of $0.1 \mathrm{~W}$ of power, continuous emission, spot area of $0.028 \mathrm{~cm} 2$, and energy of $9 \mathrm{~J}$ per application point. A gauze imbibed with $1 \mathrm{~mL}$ of methylene blue aqueous solution $(300 \mu \mathrm{M})$, which was the photosensitizer was applied to the lesion, with a pre-irradiation time of $5 \mathrm{~min}$, after which it was irradiated with red laser (RL) $[\lambda=660 \mathrm{~nm}]$ for $90 \mathrm{~s}$ per point, using the sweeping technique. The edge of the lesion was irradiated with infrared laser (IRL) $[\lambda=808 \mathrm{~nm}$ ], total energy of $5 \mathrm{~J}$, using the technique of specific points and $1 \mathrm{~J}$ of energy/point. After aPDT, low-intensity laser therapy (LILT) sessions were set up with RL and IRL, with energies of $0.5 \mathrm{~J} /$ point and $1 \mathrm{~J} /$ point, respectively. The wound was cleaned daily, protected with a bandage, and clinically evaluated until complete regression. Discussion: In the present case, methylene blue was used as a photosensitizer, but it is noteworthy that, apparently, each microorganism responds differently to photosensitizers. Thus, the therapy becomes specific for each application, for example: the type of photosensitizer, its concentration, pre-irradiation time, type of light used in photosensitization, wavelength, energy, power, mode delivery of light. Thus, for the best result, the specific protocol in each application should be used Low-intensity laser therapy is an easily executed technique with effective results. The use of PDT associated with photobiomodulation therapy enabled rapid healing of the cutaneous wound, in addition to an improvement in clinical signs and pain caused by the lesion. The technique proved to be an efficient alternative in the treatment of wounds, whether used in isolation or associated with conventional therapy.
\end{abstract}

Keywords: methylene blue, healing, wound, photobiomodulation, low-level laser. 


\section{INTRODUCTION}

Rupture of the anatomical and physiological integrity of integumentary tissue can be caused by several factors [5]. Laser photobiomodulation (LPB) has been used in the treatment of various injuries and diseases $[6,12]$. For photophysical-chemical effects to occur, the endogenous chromophore photoacceptors need to absorb the photons of irradiated light. This promotes modulation of the inflammatory process, edema reduction and devitalized tissue regeneration $[3,10]$. Laser therapy exhibit early epithelialization due to increased neovascularization and fibroblast proliferation [11].

Antimicrobial photodynamic therapy (aPDT) uses a non-toxic photosensitizer, specific light wavelength, and molecular oxygen. Interaction of the triad triggers a chemical reaction for the formation of oxygen reactive species and singlet oxygen production, enabling the destruction of microorganisms [4]. The advantages of aPDT are its easy application and the absence of side effects [2]. The short contact time of the photosensitizer with the bacteria and the simultaneous action on proteins, lipids, and nucleic acids inhibit the expression of protective factors such as stress proteins, which minimizes the possible appearance of acquired resistance [7]. Other advantages are the cost of the therapy, minimal damage to animal tissue, a broad spectrum of action, and efficiency against strains resistant to antimicrobials [12].

The aim of this study was to report the clinical alterations and their resolution in a female dog with a traumatic, contaminated wound treated with laser phototherapy as an alternative therapy method.

\section{CASE}

A 3-year-old bitch Border Collie, weighing 18 $\mathrm{kg}$, from the municipality of Ilhéus, Bahia, Brazil, was presented for examination with a history of traumatic laceration of the left thoracic member. On the anamnesis, it was reported that the patient presented with laceration of the left thoracic member. The wound was cleaned and an antibiotic ${ }^{1}$ [Cefadroxila ${ }^{\circledR}-30 \mathrm{mg} / \mathrm{kg}$ of $12 / 12 \mathrm{~h}$ ] and anti-inflammatory ${ }^{2}$ Meloxicam $^{\circledR}-0.1 \mathrm{mg} / \mathrm{kg}$ every $24 \mathrm{~h}$ ] were prescribed, both for 5 days. Twenty-four $\mathrm{h}$ after the surgical procedure, there was dehiscence of the sutures, with daily topical therapy based on zinc oxide $^{3}\left(\right.$ Alantol $^{\circledR}$ ) for secondary intention healing. Upon physical examination, the wound was found to be contaminated with swollen and erythematous edges, an ulcerated area with devitalized tissue, serous exudate, and $8.8 \mathrm{~cm}^{2}$ of wounded area (Figure 1A). Given the macroscopic characteristics of the lesion, phototherapy was associated with conventional therapy until complete healing of the wound, with three weekly applications at $48 \mathrm{~h}$ intervals. Initially, the wound was cleaned with saline solution at $0.9 \%$ and a single treatment with aPDT was scheduled due to the high degree of contamination. The dosimetry parameters of irradiation were calculated according to the wounded area with a diode laser of 0.1 $\mathrm{W}$ of power, continuous emission, spot area of 0.028 $\mathrm{cm}^{2}$, and energy of $9 \mathrm{~J}$ per application point. A gauze imbibed with $1 \mathrm{~mL}$ of methylene blue aqueous solution $(300 \mu \mathrm{M})$, which was the photosensitizer (Figure 1B) was applied to the lesion, with a pre-irradiation time of 5 min, after which it was irradiated with red laser (RL) $[\lambda=$ $660 \mathrm{~nm}$ ] for $90 \mathrm{~s}$ per point, using the sweeping technique (Figure 1C). The edge of the lesion was irradiated with infrared laser (IRL) $[\lambda=808 \mathrm{~nm}]$, total energy of $5 \mathrm{~J}$, using the technique of specific points and $1 \mathrm{~J}$ of energy/ point. After aPDT, low-intensity laser therapy (LILT) sessions were set up with RL and IRL, with energies of $0.5 \mathrm{~J} /$ point and $1 \mathrm{~J} /$ point, respectively. The wound was cleaned daily, protected with a bandage, and clinically evaluated until complete regression.

\section{DISCUSSION}

In this report, the use of aPDT was proposed as initial treatment as it causes the selective death of various microorganisms [8]. Considering the macroscopic characteristics of the wound, with loss of tissue, swollen edges, devitalization, and the presence of secretion, in addition to failure of healing by first intention, low-intensity laser therapy was also carried out. This was due to its biomodulation effects, which promote cellular homeostasis and tissue regeneration [3].

Forty-eight $\mathrm{h}$ after the first session, the lesioned area showed reduced edema and erythema, granulation tissue formation in the bed of the lesion, absence of exudate, and a reduction of $3.8 \mathrm{~cm}^{2}$. This improvement in the wound after one laser therapy session corroborated the literature, which described the production of oxygen reactive species and singlet oxygen by aPDT that promoted the death of bacterial microorganisms. With the addition of the effects of laser photobiomodulation, this favored the modulation of inflammation, and reduction of pain and edema [1]. They also promote a significant decrease in the lesioned area and the presence of granulation tissue (Figure 2A). 
The second session was with RL $[\lambda=660 \mathrm{~nm}]$ and IRL $[\lambda=808 \mathrm{~nm}]$, using energies of $0.5 \mathrm{~J} /$ point and $1 \mathrm{~J} /$ point, respectively. In the third session, aPDT was carried out once again, due to the patient having contaminated and injured the granulation tissue in the wound (Figure 2B). Two points were irradiated with $9 \mathrm{~J}$ of energy, RL on the ulcerated area and 5 stitches, with $1 \mathrm{~J}$ of energy, and IRL on the edge of the lesion. The 4 following sessions were with RL on the bloody area, at an energy of $0.5 \mathrm{~J} /$ point, and IRL on the edge, at an energy of $1 \mathrm{~J} /$ point, with a $48 \mathrm{~h}$ interval between sessions. A gradual increase in healing was observed, with the edge being displaced towards the center, covered by epithelial tissue, and hair growth, showing advanced morphofunctional restoration of the involved tissues (Figure 2C).

These results are caused by the photochemical effect of laser therapy, which restores cellular homeostasis. Its effects can be observed in different stages of healing, with modulation of inflammation, neoangiogenesis, analgesia, accelerated collagen deposition, and endothelial cell proliferation [3,12].

On the 14th day, the healing process was advanced, with a $0.4 \mathrm{~cm}^{2}$ area of crust and the exuberant presence of hair in the shaved area (Figure 2D). The fi-

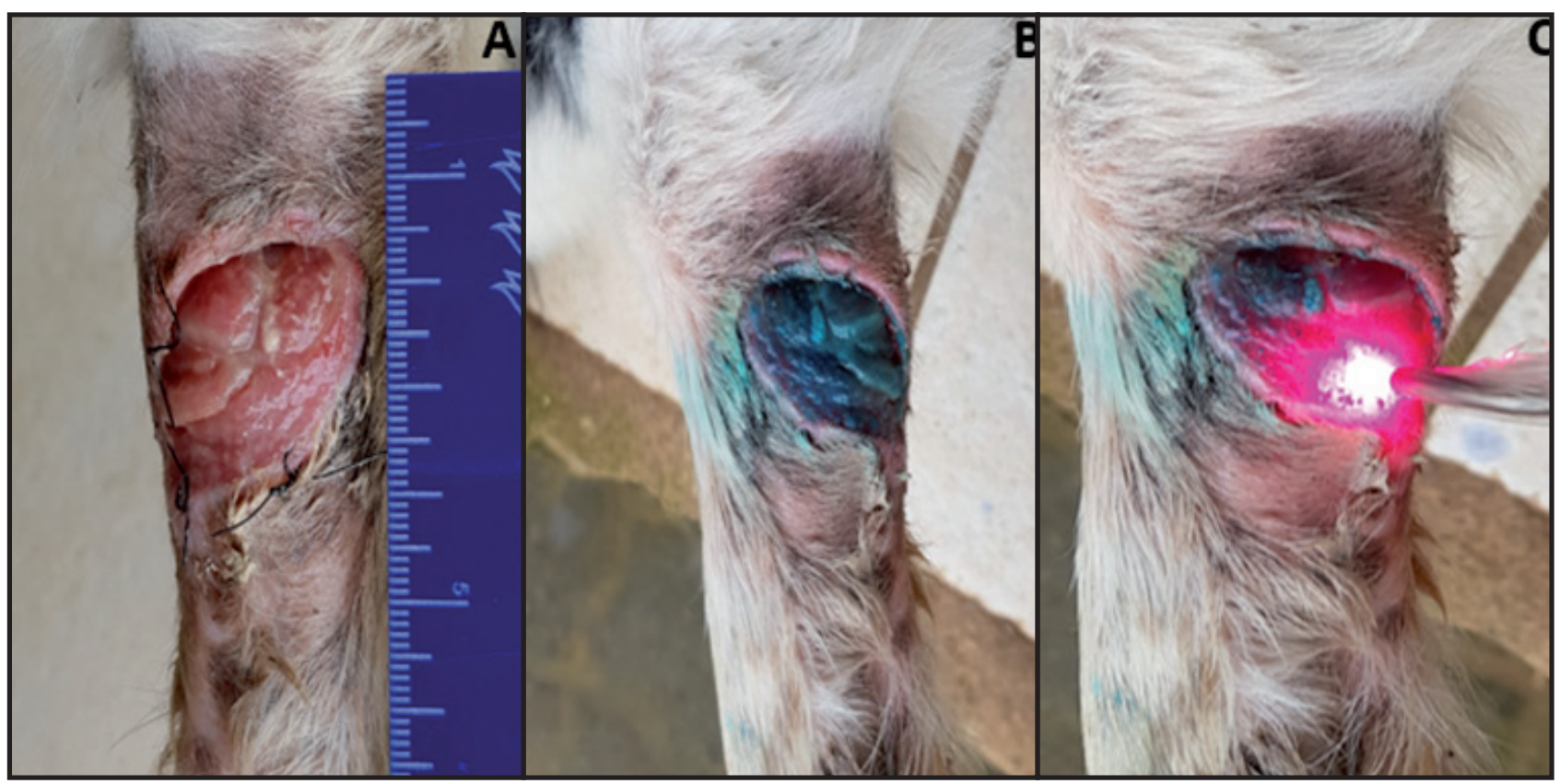

Figure 1. Contaminated wound with suture dehiscence. A- Devitalized wound, with swollen edges and serous exudate. B- Application of $0.01 \%$ methylene blue $(300 \mu \mathrm{M})$ on the contaminated wound. C- Irradiation with red laser $(\lambda=660 \mathrm{~nm})$ for $90 \mathrm{~s}$ per point, on the lesioned region.

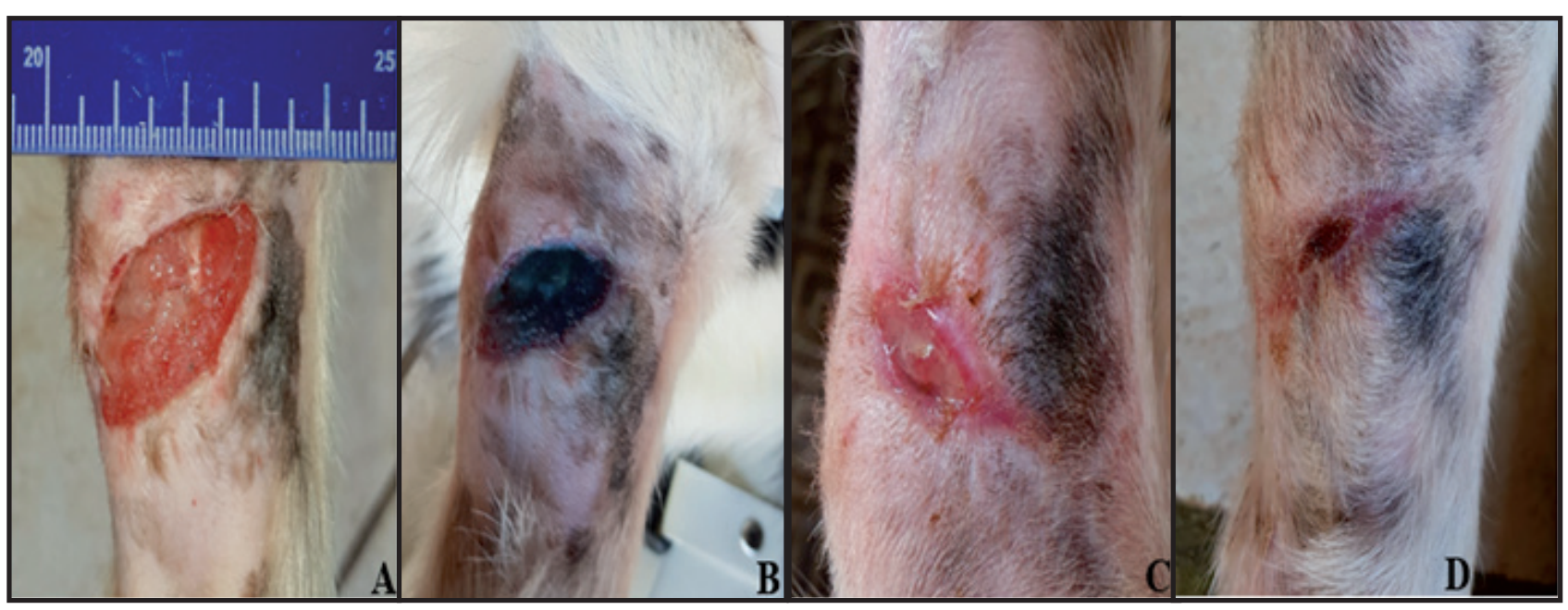

Figure 2. Healing evolution. A- Presence of granulation tissue and reduction of the wounded area $48 \mathrm{~h}$ after the phototherapy session. B- Day 5, photodynamic therapy with $0.01 \%$ methylene blue photosensitizer. C- Day 10, wound with reduction of the lesioned area and cellular migration from the edge of the wound, in the fifth session of phototherapy. D- Day 14, complete tissue repair, showing a scar with clear edges and advanced morphofunctional reestablishment of the involved tissue, albeit with a slightly uneven central portion, in the seventh phototherapy session. 
nal session of photobiomodulation was then conducted

[9] reported that laser therapy promotes the healing of chronic wounds in cases of reduced microcirculation.

In the present case, methylene blue was used as a photosensitizer, but it is noteworthy that, apparently, each microorganism responds differently to photosensitizers. Thus, the therapy becomes specific for each application, for example: the type of photosensitizer, its concentration, pre-irradiation time, type of light used in photosensitization, wavelength, energy, power, mode delivery of light. Thus, for the best result, the specific protocol in each application should be used $[1,2]$.
Low-intensity laser therapy is an easily executed technique with effective results. The use of PDT associated with photobiomodulation therapy enabled rapid healing of the cutaneous wound, in addition to an improvement in clinical signs and pain caused by the lesion. The technique proved to be an efficient alternative in the treatment of wounds, whether used in isolation or associated with conventional therapy.

\section{MANUFACTURERS \\ ${ }^{1}$ Vansil Saúde Animal. Descalvado, SP, Brazil. \\ ${ }^{2}$ Ourofino Saúde Animal. Cravinhos, SP, Brazil. \\ ${ }^{3}$ Vetnil Indústria e Comércio de Produtos Veterinários Ltda. \\ Louveira, SP, Brazil.}

\section{REFERENCES}

1 Abreu Villela P., Souza N.C., Baia J.D., Gioso M.A., Aranha A.C.C. \& Freitas P.M. 2017. Antimicrobial photodynamic therapy (aPDT) and photobiomodulation (PBM - $660 \mathrm{~nm}$ ) in a dog with chronic gingivostomatitis. Photodiagnosis and Photodynamic Therapy. 34(20): 273-275.

2 Ahad A., Lamba A.K., Faraz F., Tandon S., Chawla K. \& Yadav N. 2016. Effect of Antimicrobial Photodynamic Therapy as an Adjunct to Nonsurgical Treatment of Deep Periodontal Pockets: A Clinical Study. Journal Lasers Medicine Science. 7(4): 220-226.

3 Andrade F.S.S.D., Clark R.M.O. \& Ferreira M.L. 2014. Effects of low-level laser therapy on wound healing. Revista do Colégio Brasileiro de Cirurgióes. 41(2): 129-133.

4 Bagnato V.S., Kurachi C., Blanco K.C. \& Inada N.M. 2017. Antimicrobial Photodynamic Therapy. In: Hamblin MR, Sousa MVP. \& Agrawal T. (Eds). Handbook of Low-Level Laser Therapy. Singapore: Pan Stanford Publishing, pp.273-283.

5 Balsa I.M. \& Culp W.T.N. 2015. Wound Care. The Veterinary clinics of North America. Small animal Practice. 45(5): 1049-1065.

6 Baltzer A.W.A., Stosch D., Seidel F. \& Ostapczuk M.S. 2017. Low-Level-Laser therapie: A narrative literature review on the efficacy in the treatment of rheumatic orthopaedic conditions. Zeitschrift fur Rheumatologie. 76(9): 806-812.

7 Giuliani F., Martinelli M., Cocchi A., Arbia D., Fantetti L. \& Roncucci G. 2010. In vitro resistance selection studies of RLP068/Cl, a new Zn(II) phthalocyanine suitable for antimicrobial photodynamic therapy. Antimicrobial Agents and Chemotherapy. 54(2): 637-642.

8 Gomes J.P.F.S., Ramos R.R., Frias D.F.R., Marques V.B., Kozusnt-Andreani D.I. \& Fernandes A.U. 2016. Evidences of photodynamic therapy effect on foot rot disorders in dairy cows in the Municipality of Fernandópolis, São Paulo, Brazil. Brazilian Journal of Veterinary Medicine. 38(3): 257-264.

9 Kaviani A., Djavid G.E., Ataie-Fashtami L., Fateh M., Geodis M., Salami M., Zand N., Kashef N. \& Larijani B. 2011. A Randomized Clinical Trial on the Effect of Low-Level Laser Therapy on Chronic Diabetic Foot Wound Healing: A Preliminary Report. Photomedicine and laser Surgery. 29(2): 109-114.

10 Langella L.G., Casalechi H.L., Tomazoni S.S., Johnson D.S., Albertini R., Pallotta R.C., Marcos R.L., Carvalho P.T.C. \& Leal-Junior E.C.P. 2018. Photobiomodulation therapy (PBMT) on acute pain and inflammation in patients who underwent total hip arthroplasty-a randomized, triple-blind, placebo-controlled clinical trial. Lasers Medicine Science. 33(9): 1933-1940.

11 Rocha Júnior A.M., Oliveira R.G., Farias R.E., Andrade L.C.F. \& Aerestrup F.M. 2006. Modulation of fibroblast proliferation and inflammatory response by low-intensity laser therapy in tissue repair process. Anais Brasileiros de Dermatologia. 81(2): 150-156.

12 Sellera F.P., Gargano R.G., Libera A.M.M.P.D., Benesi F.J., Azevedo M.R, Sá L.R.M., Ribeiro M.S., Silva Baptista M. \& Pogliani F.C. 2016. Antimicrobial photodynamic therapy for caseous lymphadenitis abscesses in sheep: Report of ten cases. Photodiagnosis and Photodynamic Therapy. 13: 120-122.

http://seer.ufrgs.br/ActaScientiaeVeterinariae

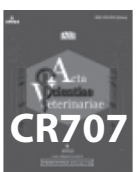

